\title{
How does BAFF activate B cells in patients with autoimmune diseases?
}

\author{
Xavier Mariette* \\ See related research by Yoshimoto et al., http://arthritis-research.com/content/13/5/R170
}

Abstract
In a study in a recent issue of Arthritis Research \&
Therapy, Yoshimoto and colleagues demonstrate that
peripheral monocytes from patients with Sjögren's
syndrome (SS) produce significantly higher amounts
of B cell-activating factor (BAFF) and interleukin-6 (IL-6)
in comparison with normal monocytes. This difference
exists at baseline and is amplified after stimulation with
interferon-gamma. Increased IL-6 secretion is partially
suppressed by an anti-BAFF antibody, suggesting
that signal transduction pathways mediated by BAFF
are implicated in the regulation of IL-6 production by
monocytes. The origin and pathways involved in this
higher susceptibility to BAFF-driven IL-6 induction by
monocytes of patients with SS are still unknown.

In a study in a recent issue of Arthritis Research $\mathcal{E}$ Therapy, Yoshimoto and colleagues [1] demonstrate that peripheral monocytes from patients with Sjögren's syndrome (SS) produce significantly higher amounts of the cytokines $\mathrm{B}$ cell-activating factor (BAFF) (also called B-lymphocyte stimulator, or BlyS) and interleukin-6 (IL-6) in comparison with normal monocytes. Increased expression of BAFF might explain pathogenic B-cell activation in several systemic autoimmune diseases (reviewed in [2]). Interestingly, autoreactive B cells depend more on BAFF for survival than do alloreactive B cells. BAFF involvement in the pathogenesis of autoimmune diseases is well illustrated in BAFF-transgenic mice, which exhibit an autoimmune disease mimicking systemic lupus erythematosus (SLE) and primary Sjögren's syndrome (pSS) as well as a twofold increase in frequency of B-cell lymphoma [3]. In humans, an increased serum level of BAFF was reported

\footnotetext{
*Correspondence: xavier.mariette@bct.aphp.fr

Service de Rhumatologie, Hôpital Bicêtre, Assistance Publique-Hôpitaux de Paris (AP-HP), Université Paris-Sud, Institut Pour la Santé et la Recherche Médicale (INSERM) U 1012, 78 rue du Général Leclerc, 94275 Le Kremlin Bicêtre, France
}

in different autoimmune diseases, and findings concerning SLE and pSS were more consistent (reviewed in [2]).

Recent findings showed that BAFF could be expressed and secreted by resident cell targets of autoimmunity after stimulation with different cytokines: synoviocytes in rheumatoid arthritis, astrocytes in multiple sclerosis, and epithelial cells in pSS [4]. Moreover, in the context of autoimmunity, BAFF could be secreted by $\mathrm{T}$ [5] and B [6] lymphocytes. However, the main sources of BAFF are myeloid cells and, especially, blood monocytes, myeloid dendritic cells, and macrophages [7].

It has been suggested that monocytes from patients with autoimmune diseases were more susceptible to BAFF expression and secretion after stimulation with type 1 interferon (IFN) than those from healthy controls [8]. Yoshimoto and colleagues [1] add an important point to this discussion by emphasizing the role of monocytes in the overproduction of BAFF in autoimmunity. The authors demonstrate that peripheral pSS monocytes produce significantly higher amounts of BAFF and IL-6 in comparison with normal monocytes. This difference exists at baseline and is amplified after stimulation with type 2 IFN, IFN- $\gamma$. Increased IL- 6 secretion is partially suppressed by an anti-BAFF antibody, suggesting that signal transduction pathways mediated by BAFF are implicated in the regulation of IL- 6 production by monocytes. Lastly, the authors find elevated expression levels of BAFF-R and different transcription factors regulating IL-6 in pSS monocytes.

We have three comments in regard to this interesting study.

\section{The differential roles of type 1 and type 2 IFN in autoimmune diseases}

Like lupus, pSS is considered to be a type 1 IFN-driven autoimmune disease (reviewed in [2]), whereas rheumatoid arthritis is supposed to be mediated mainly by TH1 and TH17 cells, and type 2 IFN is supposed to have a pathogenic role. The present study is another example emphasizing the fact that it is difficult to discriminate between type 1 and type 2 involvements in an autoimmune disease; this is quite surprising, given the 
different cells secreting type 1 and type 2 IFN. However, in experiments like those made with type 2 IFN, we would like to see the effect of type 1 IFN on pSS monocytes.

\section{The mechanism of B-cell activation induced by BAFF}

Almost $100 \%$ of B cells express BAFF-R (or BR3), the most important BAFF receptor. According to the classic understanding of BAFF-R, the action of BAFF for B-cell activation goes mainly through this receptor. However, as our group has shown in pSS [9] and others have shown in chronic hepatitis $C$ virus infection [10], there was a negative correlation between the level of soluble BAFF in the serum and the level of expression of BAFF-R on B cells. Interestingly, in the study by Yoshimoto and colleagues, it seems that, as previously observed, BAFF-R expression is normal or decreased at the surface of $B$ cells (Figure 4 of [1]). Thus, if there is a decrease in BAFF-R expression on B cells (even if the BAFF level is increased), this BAFF increase could not induce B-cell activation directly. Yoshimoto and colleagues propose an alternative mechanism: in the context of autoimmunity, the effect of BAFF on B-cell activation could be at least partly mediated by a BAFF-driven autocrine secretion of IL-6 by monocytes. The authors suggest that, in the context of SS, the monocytes may express a significant level of BAFF-R, allowing an autocrine action on BAFF on monocytes for inducing IL-6. The possibility that monocytes of patients with autoimmune diseases express BAFF- $R$ is a new finding and must be confirmed. Moreover, the inhibition of IL- 6 secretion by the adjunction of an anti-BAFF is only very partial (Figure 2 of [1]) and thus secretion of IL-6 may also be independent of BAFF. Lastly, the respective contributions of BAFF and IL- 6 on B-cell activation in the context of autoimmunity should be explored in greater depth in animal models and patients. Interestingly, in patients with lupus, it has been shown that B-cell activation was dependent on the combination of BAFF and IL-17 [11].

\section{What are the pathways implicated in this BAFF-driven IL- 6 secretion by monocytes, and why are patients with pSS more susceptible to this induction?}

Yoshimoto and colleagues found an increased expression level of IL-6-specific transcription factors and of transcription factors like nuclear factor-kappa-B in pSS monocytes compared with controls but this increased expression was constitutive and not induced by BAFF. Thus, it is necessary to do more work to study the effect of BAFF stimulation on upstream kinases and transcription factors like JAK and STAT proteins in order to look for a specific deregulation of these pathways in patients versus controls.
In conclusion, BAFF could activate B cells through other cytokines like IL- 6 and this cytokine could be an interesting target in BAFF-mediated autoimmune diseases. The mechanisms of the peculiar susceptibility of pSS monocytes to this BAFF-induced IL-6 secretion could also help in the search for new specific targets for therapy.

\section{Abbreviations}

BAFF, B cell-activating factor; BAFF-R, B cell-activating factor receptor; IFN, interferon; IL-6, interleukin-6; pSS, primary Sjögren's syndrome; SLE, systemic lupus erythematosus; SS, Sjögren's syndrome.

\section{Competing interests}

The author declares that he has no competing interests.

Published: 24 February 2012

\section{References}

1. Yoshimoto K, Tanaka M, Kojima M, Setoyama Y, Kameda H, Suzuki K, Tsuzaka K, Ogawa Y, Tsubota K, Abe T, Takeuchi T: Regulatory mechanims for the production of BAFF and IL-6 are impaired in monocytes of patients with primary Sjögren's syndrome. Arthritis Res Ther 2011, 13:R170.

2. Mariette $X$, Gottenberg JE: Pathogenesis of Sjögren's syndrome and therapeutic consequences. Curr Opin Rheumatol 2010, 22:471-477.

3. Mackay F, Woodcock SA, Lawton P, Ambrose C, Baetscher M, Schneider P, Tschopp J, Browning JL: Mice transgenic for BAFF develop lymphocytic disorders along with autoimmune manifestations. J Exp Med 1999, 190:1697-1710.

4. Ittah M, Miceli-Richard C, Eric Gottenberg J, Lavie F, Lazure T, Ba N, Sellam J, Lepajolec C, Mariette X: B cell-activating factor of the tumor necrosis factor family (BAFF) is expressed under stimulation by interferon in salivary gland epithelial cells in primary Sjogren's syndrome. Arthritis Res Ther 2006, 8:R51

5. Lavie F, Miceli-Richard C, Quillard J, Roux S, Leclerc P, Mariette X: Expression of BAFF (BLyS) in T cells infiltrating labial salivary glands from patients with Sjogren's syndrome. J Pathol 2004, 202:496-502.

6. Daridon C, Devauchelle V, Hutin P, Le Berre R, Martins-Carvalho C, Bendaoud B, Dueymes M, Saraux A, Youinou P, Pers JO: Aberrant expression of BAFF by $B$ lymphocytes infiltrating the salivary glands of patients with primary Sjogren's syndrome. Arthritis Rheum 2007, 56:1134-1144.

7. Nardelli B, Belvedere O, Roschke V, Moore PA, Olsen HS, Migone TS, Sosnovtseva S, Carrell JA, Feng P, Giri JG, Hilbert DM: Synthesis and release of B-lymphocyte stimulator from myeloid cells. Blood 2001, 97:198-204.

8. Lavie F, Miceli-Richard C, Ittah M, Sellam J, Gottenberg JE, Mariette X: B-cell activating factor of the tumour necrosis factor family expression in blood monocytes and T cells from patients with primary Sjögren's syndrome. Scand J Immunol 2008, 67:185-192.

9. Sellam J, Miceli-Richard C, Gottenberg JE, Ittah M, Lavie F, Lacabaratz C, Gestermann N, Proust A, Lambotte O, Mariette X: Decreased B cell activating factor receptor expression on peripheral lymphocytes associated with increased disease activity in Dis primary Sjögren's syndrome and systemic lupus erythematosus. Ann Rheum 2007, 66:790-797.

10. Landau DA, Rosenzwajg M, Saadoun D, Klatzmann D, Cacoub P: The B lymphocyte stimulator receptor-ligand system in hepatitis $C$ virusinduced B cell clonal disorders. Ann Rheum Dis 2009, 68:337-344.

11. Doreau A, Belot A, Bastid J, Riche B, Trescol-Biemont MC, Ranchin B, Fabien N, Cochat P, Pouteil-Noble C, Trolliet P, Durieu I, Tebib J, Kassai B, Ansieau S, Puisieux A, Eliaou JF, Bonnefoy-Bérard N: Interleukin 17 acts in synergy with $B$ cell-activating factor to influence $B$ cell biology and the pathophysiology of systemic lupus erythematosus. Nat Immunol 2009, 10:778-785

doi:10.1186/ar3729

Cite this article as: Mariette $X$ : How does BAFF activate $B$ cells in patients with autoimmune diseases? Arthritis Research \& Therapy 2012, 14:106. 